\title{
Material didático de ecologia confeccionado por alunos do curso de licenciatura em biologia: Uma análise da produção escrita
}

Didactic material of ecology made by students of the biology licensing course: An analysis of writing production

Material didáctico de ecología confeccionado por estudiantes del curso de licenciatura en biología: Un análisis de la producción escrita

Cecília Nogueira Barcelos Licenciada em Biologia, UFLA, Brasil. cecilia.barcelos@hotmail.com

Laise Vieira Gonçalves Mestre em Educação, UFSJ, Brasil. laisebiologa@gmail.com

Antonio Fernandes Nascimento Junior Professor Doutor, UFLA, Brasil. toni_nascimento@yahoo.com.br 


\section{RESUMO}

Os professores constroem ao longo de sua trajetória acadêmica e pessoal variados conhecimentos que são essenciais a sua prática. A forma como essas práticas vem sendo mobilizadas nos cursos de formação docente é um dos grandes problemas discutidos atualmente. Neste sentido foi feita uma análise das práticas realizadas durante a disciplina Metodologia do Ensino em Ecologia do curso de Licenciatura em Ciências Biológicas da UFLA. Os discentes desenvolveram diferentes estratégias didáticas, de acordo com os conceitos propostos pelos PCN a fim de facilitar a aprendizagem dos alunos. Toda atividade foi filmada. Foi possível perceber as contribuições da prática para a formação destes professores percebendo-se como é fundamental a reflexão e as discussões referentes a estas práticas.

PALAVRAS-CHAVE: Formação de professores. Metodologias. Estratégias Didáticas.

\section{ABSTRACT}

Throughout their academic and personal trajectory, teachers construct knowledge that is essential to their practice. The way these practices are being mobilized in teacher training courses is one of the major problems currently discussed. In this sense, an analysis of the practices carried out during the discipline Methodology of Teaching in Ecology of the course of Degree in Biological Sciences of UFLA was made. The students developed different didactic strategies, according to the concepts proposed by NCPs in order to facilitate student learning. All activity was filmed. It was possible to perceive the contributions of the practice to the formation of these teachers, realizing how fundamental is the reflection and the relative ones regarding these practices.

KEYWORDS: Teacher training. Methodologies. Didactic Strategies.

\section{RESUMEN}

Los profesores construyen a lo largo de su trayectoria académica y personal variados conocimientos que son esenciales para su práctica. La forma en que estas prácticas se están movilizando en los cursos de formación docente es uno de los grandes problemas discutidos actualmente. En este sentido se hizo un análisis de las prácticas realizadas durante la disciplina metodología de la enseñanza en ecología del curso de Licenciatura en Ciencias Biológicas de la UFLA. Los desarrollaron diferentes estrategias didácticas, de acuerdo con los conceptos propuestos por los PCN para facilitar el aprendizaje de los estudiantes. Toda la actividad fue filmada. Es posible percibir las contribuciones de la práctica para la formación de estos profesores percibiendo como es fundamental la reflexión y las discusiones referentes a estas prácticas.

PALABRAS CLAVE: Formación de profesores. Metodologías. Estrategias Didácticas. 


\section{INTRODUÇÃO}

A formação inicial e continuada de professores surge, no início do século XXI, como prioridade na educação brasileira.

Desde a origem das Licenciaturas no Brasil, nas antigas Faculdades de Filosofia, nos anos 30, a formação de professores depara com desencontros e dilemas, presentes até hoje. Os problemas que mais aparecem nas práticas de formação desses cursos são: a separação entre disciplinas específicas e disciplinas pedagógicas; dicotomia entre Bacharelado e Licenciatura; e, desarticulação entre formação acadêmica e realidade prática. Toda essa situação já vem sendo estudada desde a década de 80 , onde se iniciou o processo de reforma educacional (ALMEIDA, 2005).

Uma nova etapa de reforma surgiu com a promulgação da Lei no 9.394/96, a Lei de Diretrizes e Bases da Educação Nacional (LDB). Ela consolidou e tornou norma uma ressignificação do processo de ensinar e aprender: determinou um modelo curricular na qual os conteúdos de ensino são compreendidos como subsídio para gerar aprendizagem e competências nos alunos (MELLO, 2000).

Logo após a LDB, são aprovadas as Diretrizes para Formação de Professores da Educação Básica, que marca um momento de transição nos cursos de Licenciatura. As Diretrizes Curriculares configuram-se numa proposta de formação que pretende superar o modelo formativo que prevaleceu desde o surgimento do curso de Licenciatura (ALMEIDA, 2005).

No executivo, o MEC elaborou um currículo nacional, os Parâmetros Curriculares Nacionais (PCN) que engloba toda a educação básica. O documento está disponível, em caráter de recomendação, a todos os sistemas e escolas (MELLO, 2000).

Tendo em vista que atualmente as instituições vivenciam um processo de adequação curricular, devemos pensar em como essa reforma está sendo articulada na formação inicial e continuada de professores.

A Educação deve ser adequada às mudanças que a sociedade vem enfrentando para a formação de um novo cidadão. Pensar em educação pressupõe pensar a formação docente e a prática pedagógica com qualidade (BANDEIRA, 2006).

\section{OBJETIVOS}

Nesse sentido, a proposta do trabalho foi de analisar as práticas pedagógicas realizadas durante a disciplina de Metodologia de Ensino em Ecologia do curso de Licenciatura em Ciências Biológicas da Universidade Federal de Lavras, UFLA, MG.

\section{METODOLOGIA}

Este trabalho se insere no campo das pesquisas qualitativas. A abordagem qualitativa é um método de investigação científica que se preocupa com o porquê de determinados fenômenos, não apenas com a quantificação de dados, mas sim com sua realidade social (MINAYO, 2001). Para analisar as falas foi utilizado o método de categorização, que é uma 
análise derivada da análise de conteúdo, conforme apresentada por Minayo (2000). A análise de conteúdo busca, a partir do objeto de estudo, colocar maior significação ao que foi relatado e, desse modo, interpretar de forma fiel a ideia central e real dessas falas, como apontado por Mozzato e Grzybovski (2011).

3.1 Descrição e apresentação das estratégias de ensino elaboradas pelos alunos da disciplina de metodologia do ensino em ecologia

A disciplina Metodologia do Ensino em Ecologia do curso de licenciatura em Ciências Biológicas da Universidade Federal de Lavras (UFLA), MG, tem como objetivo desenvolver estratégias para o ensino dos temas de ecologia no ensino médio. Tais temas são aqueles propostos pelos PCN. O presente trabalho procurou relatar tais atividades e, em seguida avaliá-las sob a ótica dos licenciandos do curso de Biologia e dos alunos e professores integrantes do Programa Institucional de Bolsas de Iniciação à Docência (PIBID).

O estudo foi feito observando a produção dos alunos da disciplina durante o primeiro semestre de 2013. Neste período foi desenvolvida uma atividade na disciplina relatada a seguir.

Inicialmente os alunos escolheram um assunto sugerido pelo PCN, dentro da temática ecologia. Cada tema recebeu símbolo T que possibilita a identificação e o acompanhamento dos resultados da análise. Os conceitos selecionados foram: T1) Biogeografia de ilhas. T2) Características de um ecossistema; T3) Interações ecológicas; T4) Transferência de energia no ecossistema; T5) Ciclos Biogeoquímicos; T6) Transferência de energia entre indivíduos; T7) Reaproveitamento de materiais; T8) Tipos de poluição e áreas poluídas; T9) Interferência humana nos ciclos materiais; T10) Problemas ambientais e sustentabilidade.

Em seguida procuraram elaborar estratégias metodológicas utilizando diferentes ferramentas pedagógicas para trabalhar os conceitos selecionados. As estratégias escolhidas foram: excursão, dinâmica, experimento, modelo, jogo interativo, textos educacionais, imagens, vídeo, história do Brasil e filosofia da ciência. Cada uma destas formas de se ensinar foi estudada pelos alunos no sentido de adequá-la a cada tema escolhido. 0 quadro 1 mostra a relação entre cada assunto e sua respectiva estratégia. 
Quadro 1. As estratégias desenvolvidas pelos discentes durante o ano letivo de 2013 na disciplina de metodologia do ensino em ecologia.

\begin{tabular}{|c|c|}
\hline ASSUNTOS & ESTRATĖGIA GERAL DE ENSINO \\
\hline T1) Características de um ecossistema & Excursão \\
\hline T2) Interações ecológicas & Dinâmica \\
\hline $\begin{array}{l}\text { T3) Transferência de energia no } \\
\text { ecossistema }\end{array}$ & Experimento \\
\hline T4) Ciclos Biogeoquímicos & Modelo \\
\hline $\begin{array}{l}\text { T5) Transferência de energia entre } \\
\text { indivíduos }\end{array}$ & Jogo interativo \\
\hline T6) Reaproveitamento de materiais & Textos educacionais \\
\hline T7) Tipos de poluição e áreas poluídas & Imagens \\
\hline $\begin{array}{l}\text { T8) Interferência humana nos ciclos } \\
\text { materiais }\end{array}$ & Vídeo \\
\hline $\begin{array}{l}\text { T9) Problemas ambientais e } \\
\text { sustentabilidade }\end{array}$ & História do Brasil \\
\hline T10) Biogeografia de ilhas & Filosofia da Ciência \\
\hline
\end{tabular}

Uma vez elaborada, as estratégias didáticas foram expostas no I Simpósio de Práticas do Ensino de Ciências e Biologia, realizado no Museu de História Natural da Universidade Federal de Lavras no período de 19/09/2013 a 23/09/2013 com o propósito apresentar os trabalhos finais aos alunos graduandos em Ciências Biológicas Licenciatura, pelos bolsistas do PIBID (Programa Institucional de Bolsas de Iniciação à Docência), do curso em questão e professores da educação básica.

Ao final da disciplina cada aluno responsável por seu trabalho, apresentava um texto onde descrevia e analisava todo o processo exibido contendo: Título, Introdução, Justificativa, Objetivos, Metodologia, Resultados, Discussão, Conclusões e Referenciais.

Cada uma das estratégias metodológicas foi apresentada a maneira de uma aula habitual. Ao final de cada exposição os expectadores apresentavam oralmente suas impressões sobre o exposto. Toda a atividade foi filmada. Ao final da apresentação de cada aula os participantes avaliaram a prática e a ferramenta utilizada. 


\section{RESULTADOS}

A partir das falas dos participantes do simpósio foi possível refletir e analisar as mesmas. As falas relatadas abaixo foram transcritas da gravação da apresentação do trabalho de metodologia do ensino em ecologia, no I Simpósio de Ensino de Ciências e biologia. Os participantes autores das falas são identificados pela letra $P$ indicando professores e $A$ indicando alunos.

T1- A utilização de Excursões no Ensino de Ecologia: uma abordagem acerca das características de um Ecossistema

A1: [...] uma imagem traz muito mais, então você pode discutir a mesma imagem por muito tempo. Foi muito legal, pelo grupo todo. Eu falo isso enquanto aluna da disciplina mesmo, porque a visão que a gente traz de excursão é exatamente o que você falou né, nossa que trabalho eu vou ter arrumar ônibus, vou ter que não sei que e quando. Você começa a partir do pressuposto que as coisas que estão ao seu alcance podem ser usadas e estão sendo usadas de maneira correta. É muito interessante as discussões que a gente teve na disciplina, também foram muito importantes. Parabéns a sua metodologia ficou muito legal e tenho certeza que os alunos irão gostar bastante.

A2: É muito bom este tipo de metodologia, porque esta maneira como você envolve o aluno e tem essa participação ativa, é muito bom, é muito interessante.

A3: Não sei se você já ouviu falar em Célestin Freinet que é um pedagogo francês, que vai tentar justamente dar uma aula-passeio e ele quebra este paradigma de que eventos pedagógicos precisam ser dessa maneira que a gente construiu, com ônibus, lanche, piquenique e é muito interessante o que ele fala, justamente da participação efetiva do aluno no processo da construção e o modo com que o aluno se vê envolvido na técnica [...] você trabalha o aluno com o que realmente é importante, sabe que não está ali só porque a professora está dizendo e isso é muito importante e parabéns.

A4: Eu acho que é válido sim. Esta metodologia pode ser aplicada sim, porque eu falo por experiência própria que quando você pediu as fotos você me envolveu bastante [...], o que será que ela pode falar disso, de um ecossistema, porque dentro de um ecossistema a gente pode pegar assim, outros ganchos assim, então a mesma percepção que eu tive nesse trabalho, os alunos também pode ter e eu achei legal.

\section{T2 - Dinâmica como ferramenta de ensino no estudo de interações ecológicas}

A1: Eu gostei demais, muito interessante e tem que correr mesmo. $O$ problema aqui foi o espaço, mas muito legal. Eu ia me divertir bastante.

P1: Imagina para nós fazer isso. Falam o tempo inteiro, eles gritam mesmo. $O$ aluno tem que sair do espaço de sala de aula porque senão os vizinhos não aguentam, mas vai ser bom. Vão surgir tapas, vai aluno tirar aproveito. Mas acho que a gente diverte.

A5: Eu achei muito interessante, principalmente que fala tanto da questão da fragmentação do conteúdo e essa parte que você, principalmente em ecologia, que não tem como você separar muita coisa, você tem uma visão muito grande, tem o nível trófico, fluxo de energia, questão 
da interação e você pode dinamizar ainda mais, colocar mais um tipo de interação, pode colocar outros conceitos envolvidos.

\section{T3- A experimentação como meio para o ensino da ideia de transferência de energia no ecossistema}

P1: Esta parte de experimentação é válida. Eu já trabalhei assim, só com a parte de laboratório, principalmente nas sextas. Metade da turma trabalhava só com laboratório e a outra metade fazia a teoria. A experimentação é excelente, porque ele constrói realmente o conhecimento, ele induz o aluno a questionar.

A5: Na verdade eu não sou uma amante fiel a experimentação, mas eu gostei de como você resolveu aplicar ela, porque o problema da experimentação é que ela pode ser muito demonstrativa, daí os alunos vão pegar e achar que a energia já está lá e pronto. Mas o bacana é justamente isso, fazer com que a experimentação que tem sido uma metodologia muito mais demonstrativa historicamente falando, seja construtivista também sabe, que ela consiga construir o conhecimento e você foi muito bem.

T4- Modelos no Ensino de Ciências e Biologia: A Utilização do terrário para trabalhar os Ciclos Biogeoquímicos

P6: A prática é até muito boa. Mas temos que arrumar um cantinho para ficar lá na escola, eu já fiz isso lá. Chamo meia dúzia, vai lá vê o que está acontecendo depois, outro dia chamo mais outra turma diferente.

A5: Ficou muito instigante, este modelo é instigante na hora de fazer atividade. Vai ficar bom.

\section{T5- A utilização de um jogo interativo para o ensino da transferência de energia entre} indivíduos

A1: Eu achei bem bacana porque a simplicidade [...] não quer dizer reduzir ou diminuir uma coisa para caber menos conteúdo.[...] é questão de associação, assimilação do conteúdo e é uma coisa muito fácil né professora, acho que a gente pegar e manipular também.

A3: Gostei muito da sua didática, legal. Parabéns. Assim primeiro você tinha falado que a sua atividade seria feita em uma cozinha e isso seria feito na escola, não sei se seria viável, assim para uma sala grande. Acho outro campo que você poderia trabalhar é pegar as áreas das ciências, mais específico para química, eu falo tipo assim, porque uma massa se desprende com mais facilidade que a outra, o que tem a ver, se tem a ver com moléculas.

A4: Você pode trazer também na próxima, comparando com a gente. $O$ ser humano se ele ingerir muita energia, se ele comer muito a tendência dele é engordar. Mas se a pessoa, se ela gastar muita energia. Então você está trazendo para o ser humano para próximo dele uma realidade semelhante.

A5: Achei legal porque suas perguntas foram bem problematizadoras. Você questionou a gente, você instigava exatamente quando a gente começava a enxergava o processo. Então isso facilitava a gente ter compreensão sabe associar mesmo. Igual você falou assim: se eu fizer isso o que que está acontecendo, quando ela está fazendo isso, quem vai consumir o final dessa energia sabe. Foi bem legal que na sua atividade. você conseguiu falar as perguntas 
exatamente na hora. Acho que foi muito legal construir assim, mesmo, apesar da gente estar mais habituado ao conceito acho que você conseguiria construir sim.

P1: Consegue. Assim no início só, as perguntas que você fez no início, dependendo da faixa etária eles não conseguiriam construir, você teria que instigar um pouquinho mais. Foi bem didático. Parabéns.

A6:[...] O bom é a simplicidade do material, o recurso é barato, fácil de ser manuseado, não oferece perigo para os alunos no sentido que às vezes a gente vê os experimentos tendo um limite do que pode ser manuseado ou não, e eu vejo que dá para você trabalhar várias situações que você falou

A7: Gostei muito. Acompanhei o seu desenvolvimento e suas dúvidas, e você resolveu bem a questão, e acho que professor também é isso, toda hora tentar achar uma metodologia [...].

T6 - A utilização de textos educativos como ferramenta pedagógica para o ensino de Reaproveitamento de Materiais

A1: Achei muito bacana seu trabalho. Legal a formação dos grupos para construir um texto[...]Outro ponto que eu queria ressaltar também é essa importância que você dá na leitura, fazendo com que o aluno escreva. Que a gente vê que ainda tem uma dificuldade na escrita, em refletir sobre o assunto, frases que são desconexas, começa com um assunto depois vem com outro diferente, questão de pontuação e concordância. Gostei bastante.

A2: [...] da ferramenta ter isso, escrita como prática pedagógica e as vezes a gente olha e vê que a prática tão simples e tão recorrente, a gente até menospreza dizendo que não vai ficar lúdico, que não vai ser interessante trabalhar dessa forma e o texto fala que, para além do aprendizado da língua, a gente sabe que existe um déficit muito grande nos nossos alunos hoje [...] "Dar vazão a criatividade, conectar o aluno com seu interior através da escrita" ela usou esta frase e acho que a ferramenta como você diz é como o professor conduz, desse modo fica uma coisa muito interessante para ser feita. Parabéns.

A3: [...]Eu vi que tem importância você instigar pelo menos a escrever um pouco, usar esta prática de escrita e leitura, entender o que você mesmo escreveu porque o déficit nessa questão é bem notório [...]Então instigar desta forma em grupo achei bem interessante a dinâmica de grupo, do texto quando está lendo. Parabéns.

A4: Fui bem contemplado pela fala da colega exatamente por pegar uma ferramenta que já é utilizada sem ter esse caráter mais lúdico, do aluno construir coletivamente e ter contato com outras visões da mesma produção, do mesmo assunto ele está tendo este contato de visões diferentes, ele conseguirá construir melhor então acho que a atividade é muito eficaz assim. Justamente por conseguir fazer o aluno a pensar, refletir interagir também na construção. Muito bom.

A6: Gostei. Muito interessante principalmente o fato de fazer a divisão de grupos, porque daí não fica tão concentrado, um vai ajudando o outro, um fala uma coisa e o outro complementa. Bastante interessante.

P1: É bom está trabalhando isso até em atividades aqui que a gente vê que é interessante trazer coisas inovadoras, coisas diferentes mas a gente esquece que tem algumas coisas que a gente subestima acha que é muito básico não é válido e leitura e escrita é comunicação. Coisas 
corriqueiras, cotidianas que faz uma diferença muito grande na vida de uma pessoa. E está estimulando isso o tempo todo pode estar ajudando no conhecimento do aluno, na construção do aluno.

P2: Gostei bastante da sua finalização com essa questão aí que na presença do texto educativo que vai produzir mais a utilização adequada em função de uma ação educativa de uma linguagem [...] Quero te parabenizar pela proposta da questão da metodologia do trabalho com texto. Só para chamar atenção também que eu sei que com tempo desse não dá para abordar tudo né? mas essa ideia de trabalhar a metodologia é bastante relacionada aos objetivos e ao conteúdo, as concepções.[...] porque acaba que o texto ele traz um pouco uma ideia natural do ecossistema, uma movimentação natural e também traz como se fosse uma ideia de ambiente que a gente tem trabalhado com os alunos também a questão de recolocar o ser humano como um dos seres vivos também porque na verdade você tem relações aí que não são tão dependendo do contexto[...] quer dizer a gente tem ecossistemas e situações que nós não temos o reaproveitamento de materiais e muitas vezes ele não é uma coisa natural você tem várias outras condições ali se você pensar o ambiente de uma forma mais complexa né, você vai ter uma série de questões aí que não vão ser naturais. A proposta do trabalho realmente é bem interessante, da leitura e da produção do texto, com a linguagem própria do estudante e não uma linguagem memorizada puramente. Parabéns.

\section{T7- Utilização de imagens para o ensino dos Tipos de Poluições e Áreas Poluídas}

A1: Eu achei da hora como algumas pessoas colocaram este momento social, mas aí tem que tomar cuidado porque talvez não aconteça lá na escola, tem que fazer o aluno pensar, não sei a problematização das imagens para tentar conseguir essa ideia mesmo, porque a gente vê que falta muito.

A3: Achei muito legal como você abordou só que eu penso que a criticidade que a gente começou a colocar nas nossas falas, na discussão corre muito o risco de não aparecer na escola. Então você tem que ter alguma mediação para que isso aconteça porque senão a maioria vão ser fundos de educação ambiental conservacionista tipo foi o nosso, por exemplo. A10: Importante esta questão da visão crítica na educação ambiental, acho que é importante também identificar os sujeitos sociais que estão envolvidos nos trabalhos. E é uma coisa que a gente pode enxergar mais de uma maneira a questão dos brinquedos na praça, por exemplo, porque é um trabalho, alguém trabalhando e isso pode ser uma questão, da onde vem aquele material e porque existe esse tipo de trabalho é uma coisa que surgiu bastante pelo menos nas práticas que eu fiz na sala de aula, entrou muito essa questão que como faz muito parte da realidade dos meninos geralmente eles têm mais facilidade de entender a ideia. Então acho que é uma questão importante.

\section{T8- A utilização de vídeos no ensino da Interferência humana nos ciclos materiais}

A3: Só gostaria de salientar, primeiro parabéns, legal, quer dizer achei muito bom. Mas a questão é o seguinte, porque eu assisti esse vídeo também na escola e queria salientar que toda esta biologia questionável é importante [...] porque na minha época foi só uma simples exposição do vídeo, sem questionamento nenhum.[...] 
P1: Quando eu passo esse vídeo eles questionam sempre o que é o lixo na realidade, porque o que é lixo para mim, as vezes não é lixo para uma outra pessoa que tem o poder aquisitivo menor, eles ficam muito questionando o que é o lixo. Daí eu mostro para eles do problema do consumo exagerado, que aquelas pessoas que tem o poder aquisitivo menor não tem condições de comprar nem a comida e a comida sobra. É um vídeo que choca né.

T9 - História do Brasil como ferramenta pedagógica no ensino de ecologia ("Problemas ambientais brasileiros e o desenvolvimento sustentável: uma relação possível?").

P1: Parabéns, o trabalho realmente é muito bonito, de você conseguir trazer a questão teórica para a metodologia. Esta questão da história, como nosso querido Marx já dizia: a história é a grande ciência, nada é possível fora da história. Então assim, você também foi respondendo as questões e foi colocando esse destaque, a proposta interdisciplinar, a proposta mesmo que disciplinar ela teria que ser desenvolvida em várias aulas, em vários temas [...] outra coisa é a ideia da economia, quando a gente está pensando em ampliar conceitualmente algumas coisas e fugir do pejorativo que foi sendo criado, pra gente pensar em política, pensar em poder, em economia sempre com coisas muito restritas, e muito pesadas que elas ficaram com essa ideia pejorativa, no mundo interior do capitalismo né. Eu acho que o seu trabalho traz essa beleza também de poder recuperar o conceito de economia. Então nós podemos pensar em outra possibilidade de economia, então até a própria ideia da subsistência, do valor de troca das coisas e tudo mais é uma forma de economia então ampliar um pouco esse conceito também eu acho que é importante para mim.

A3: Gostei bastante, da ideia de extrativismo também, eu gosto de trabalhar essa coisa de interdisciplinaridade porque eu acho que não é uma coisa fácil, tem professores que não gostam de misturar, da ajudar assim e como você pensaria.

\section{T10- A perspectiva Fleckiana no ensino de Biogeografia de ilhas}

A1: [...] acho interessante a ideia do trabalhar com a formação inicial de professores e continuada né; por causa do déficit e tudo mais. Foi uma visão que eu não tinha pensado ainda em, trabalhar a filosofia dessa forma imagina com o conceito de biogeografia de ilhas. Nem imaginava que podia acontecer uma coisa desse tipo, foi muito legal!

\subsection{Análise dos comentários dos participantes sobre as estratégias}

Quando nos reportamos à utilização de Excursões no Ensino de Ecologia: uma abordagem acerca das características de um Ecossistema encontramos nas falas, A1 e A4, o comentário sobre o pensamento errôneo que a maioria dos professores tem em relação à utilização das excursões no ensino. Diante desse fato, A1 relata a importância que teve as discussões ocorridas durante a disciplina, justamente para desconstruir esse pensamento, pois a disciplina permitiu a reflexão para outras possibilidades a serem trabalhadas durante a construção das estratégias. A utilização da excursão para o processo de ensino aprendizagem ainda é muito confusa por parte dos professores. A maioria mantém-se pragmáticos em relação ao seu 
planejamento. Acreditam que a única forma de inserir esta prática é fazendo-a longe do ambiente escolar. Desta forma, apontam diversas dificuldades que a comunidade escolar enfrenta, entre elas, a falta de tempo para planejar, entraves burocráticos e financeiros e o preconceito de outros professores (VIVEIRO, 2006). Ao pensarmos sobre a excursão como forma de ensinar, Carbonell (2002) afirma que são essenciais espaços físicos, simbólicos e afetivos para estimular o desenvolvimento da aprendizagem. As falas A2, A3 e A4 gostaram da forma como foi conduzida a prática pela discente, destacando como é capaz de envolver quem está assistindo, o que seria um ponto positivo em sala de aula. Um dos fatores essenciais ao se trabalhar com educação é a motivação, interesse e o prazer na profissão. Assim o ensino se torna prazeroso e encantador, permitindo um aprendizado mais eficiente. A4 contribuiu muito quando citou o pedagogo Freinet, responsável pelas aulas-passeios. Ele percebeu que conseguiria ensinar conceitos teóricos de forma mais interessante e prática, e a criança sentiria prazer em aprender (COSTA, 2011).

Já, na experimentação como meio para o ensino da ideia de transferência de energia no ecossistema, A1 e A5 gostaram quando o discente falou a palavra construir. Ao pensarmos sobre o que significa a construção do conhecimento nos dias atuais, notamos que vem sendo reconhecido como uma nova maneira de pensar a forma de educar. $\mathrm{O}$ aluno para chegar nesse processo precisa ser instigado a saber pensar, a saber, observar e, a saber, questionar. Para isso o professor precisa ser o mediador desse processo. Como diz Freire (2002), ensinar não é simplesmente explicar os conteúdos para os alunos, mas ajudá-lo a construir e produzir o conhecimento. As falas P1 e A5 argumentam sobre a utilização do experimento em sala de aula, ressaltando que sua utilização é feita de maneira expositiva. O uso de Experimentos Científicos no ensino de ciências, desde que numa perspectiva coerente, permite ao aluno a formulação de hipóteses para um determinado problema por ele apropriado. Sendo assim, ele pode identificar a contradição entre a hipótese por ele formulada e a própria evidência e, ainda, pode demarcar o limite da hipótese feita. Os experimentos são excelentes ferramentas pedagógicas que possibilitam unir teoria à prática, permitindo uma aproximação do mundo real: contexto, cotidiano e teoria (REGINALDO et. al., 2012).

No que diz respeito aos modelos no ensino de ciências e biologia: a utilização do terrário para trabalhar os ciclos biogeoquímicos, P6 expressa: "A prática é muito boa", e A5 completa "Ficou muito instigante", estes relatos demonstram a relevância do uso do terrário nas escolas. Ele permite o aluno a construir todo o processo, estimulando-o na busca de explicações para os fenômenos investigados, incluindo suas contribuições através de suas ideias e questionamentos, além de possibilitar uma melhor compreensão de conceitos apropriados a ciências (BOTELHO, 2008).

Na utilização de um jogo interativo para o ensino da transferência de energia entre indivíduos, A1 e $A 6$ argumentaram que o recurso utilizado pode ser usado nas escolas, pelo fato de ser um material de fácil acesso. Muitos professores reclamam da falta de material pedagógico para o ensino, mas não procuram refletir sobre o uso de recursos que podem ser elaborados a partir de simples objetos. E como A1 relata: "não quer dizer reduzir ou diminuir uma coisa para caber menos conteúdo", pois, ter recursos sofisticados e caros não é significado de aprendizagem. 0 que é importante é como esse material será explorado junto à proposta pedagógica. 
Novamente a interdisciplinaridade, contextualização e construção do conhecimento aparecem nas falas de alguns participantes (A3, A4, A5 e P1). A7 vem falar sobre a dificuldade que os professores possuem na busca por uma metodologia adequada ao que se quer ensinar. Desta forma, ao abordar sobre a estratégia do uso de jogos interativos no ensino de ciências, verificamos ser um método didático que depende da disponibilidade e criatividade, porém é de grande valia ao permitir confirmar e construir novos conhecimentos (SOUZA e BARROS, 2012).

Quanto a utilização de textos educativos como ferramenta pedagógica para o ensino de Reaproveitamento de Materiais, na análise das falas podemos perceber que todos enfatizaram a importância da leitura e escrita para a compreensão, principalmente pelo fato dos alunos apresentarem dificuldades em interpretar. $O$ uso de textos educativos como ferramenta pedagógica pode ser eficiente na abordagem de conteúdos relacionados ao reaproveitamento de materiais nos ecossistemas, uma vez que o texto é a unidade básica da linguagem verbal, além de instigar a leitura e provocar reflexão no aluno. Como bem afirmam Schneuwly e Dolz (1999), a escola é o verdadeiro lugar de comunicação. Os gêneros textuais fornecem um suporte para a atividade desenvolvida além de serem essenciais para os educandos.

Na utilização de imagens para o ensino dos Tipos de Poluições e Áreas Poluídas, todas as falas foram categóricas ao se referirem da importância do uso de imagens como forma de aprendizagem. A1, A3 e A10 abordaram da necessidade de estar instigando o aluno para os aspectos sociais, possibilitando o senso-crítico. A utilização do material visual instiga a sua leitura de forma crítica, despertando a criatividade dos alunos. Além disso, ensina-lhes a ordenar as ideias para poder expor e defendê-las perante os colegas, a ouvir críticas e debatêlas. Segundo Santos (2006), O uso de imagens visuais faz com que a percepção, crítica, imaginação, fantasia e sentimentos sejam desenvolvidos. Seu uso em sala de aula permite o aluno pensar, além da arte, sobre várias questões e faz com que possa ser crítico e pensante na sociedade.

Falando da utilização de vídeos no ensino da Interferência humana nos ciclos materiais, podemos observar que os participantes gostaram da maneira reflexiva que a metodologia foi conduzida. Muitos comentaram da possibilidade que a ferramenta traz para a formação do senso crítico. O vídeo é um jeito dinâmico de apresentar o conteúdo. Mas, como A3 comenta, isso vai depender da maneira de como ela é apresentada. Segundo Vasconcelos e Leão (2009), o vídeo não se limita apenas como recurso didático, mas possibilita meios de auxiliar na (re) construção do conhecimento.

$\mathrm{Na}$ história do Brasil como ferramenta pedagógica no ensino de ecologia ("problemas ambientais brasileiros e o desenvolvimento sustentável: uma relação possível?"), P1 e A3 comentaram novamente sobre a interdisciplinaridade como uma das formas de utilizar essa estratégia. As outras falas gostaram da abordagem através da História do Brasil como forma de ensinar o conteúdo. Assim, Castro e Carvalho (1992) comentam, a introdução da área da história pode ser interessante e compreensível ao aplicar o conteúdo científico, pois traz o aluno mais perto do universo cognitivo e constrói historicamente o que conhece.

E, por último, na perspectiva Fleckiana no ensino de Biogeografia de llhas, podemos perceber na análise da fala A1 uma admiração em relação ao uso de filosofia como forma de ensino de 
ciências. A estratégia de utilizar a filosofia no processo de ensino de ecologia se mostra como uma ferramenta de extrema importância ao promover o conhecimento e saberes indispensáveis para a democracia. Conforme Borin (1996), a filosofia reforça a tarefa da educação, fazendo os alunos a racionar melhor, a pensar com autonomia, promovendo a compreensão da realidade com consciência e senso crítico. Apesar de sua relevância, podemos perceber que não é uma prática comum nas escolas, pois a maioria dos professores não tem claro para si sobre o que é filosofia. Outro ponto que podemos inferir foi a ausência da disciplina por muitos anos no contexto escolar. No Brasil, a disciplina sempre esteve a mercê dos intelectuais, sendo deixada de lado no ensino público. Apesar de ter sido incluída nos currículos oficiais, carece de uma razoável carga horária (TOMAZETTI, 2002).

\section{CONCLUSÃO}

Foi possível perceber, a partir das experiências vivenciadas na disciplina, a importância das práticas pedagógicas durante a formação acadêmica. Os trabalhos apresentados surgiram como uma oportunidade de unir teoria à prática, e também como uma maneira de tornar a teoria mais evidente. Esse fato contrapõe ao cenário acadêmico e escolar, onde não há essa articulação com os currículos. Dessa forma é necessário construir e aplicar na prática um currículo contextualizado, voltado para a compreensão da realidade dos alunos.

Podemos considerar que o discente ao participar da elaboração da atividade, se tornam aprendizes e ao mesmo tempo constroem conhecimentos sobre o que é ser professor, o que e como se ensina. Essa compreensão ajuda nas mudanças e questionamentos da sua própria prática, permitindo sempre uma auto avaliação. A experiência de planejar e produzir uma estratégia didática promoveu a criatividade dos estudantes, da mesma forma que contribuiu para a reflexão do papel do professor nos dias atuais.

Ensinar ciências representa um desafio para os docentes, uma vez que seu conteúdo é de difícil entendimento por parte dos alunos. Pensar em meios de realizar a inter-relação entre sala de aula e cotidiano é pensar em novas formas didáticas e metodológicas. Nesse sentido a utilização de diferentes possibilidades de ensinar contribui de maneira positiva na educação.

\section{AGRADECIMENTOS}

FAPEMIG e CAPES/PIBID

\section{REFERÊNCIAS BIBLIOGRÁFICAS}

ALMEIDA, P. C. A. Os saberes necessários à docência no contexto das reformas para a formação de professores: o caso da psicologia da educação. Tese de Doutorado. Tese de Doutorado, Faculdade de Educação, Universidade Estadual de Campinas, Campinas, SP. 2005.

BANDEIRA, H. M. M. Formação de professores e prática reflexiva. In: IV Encontro de Pesquisa em Educação da UFPI. A pesquisa como mediação de práticas socioeducativas. Teresina: EDUFPI, 2006. 
BRASIL. Lei de Diretrizes e Bases da Educação Nacional. Lei 9394 de 20 de dezembro de 1996.

BRASIL. Ministério de Educação. Parâmetros Curriculares Nacionais: terceiro e quarto ciclos. Secretaria de Ensino Fundamental. Brasília: MEC/SEF, 1998.

BORIN, J. Jogos e resolução de problemas: uma estratégia para as aulas de matemática. SãoPaulo: IME - USP, 110 p. 1996.

BOTELHO, L. A. O Terrário como Instrumento Organizador da Aprendizagem em Ciências da $8 \underline{a}$ Série (9o ano). 2008

CARBONELL, J. A aventura de inovar: a mudança na escola. Porto Alegre: Artmed. (Coleção Inovação Pedagógica). 2002.

CASTRO, R. De S., CARVALHO, A. M. de PESSOA. História da Ciência: Investigando como usá-la num curso de segundo grau. Caderno Catarinense de Ensino de Física, Florianópolis, 1992.

COSTA, M. C.C. Freinet: suas contribuições ao processo de sensibilização ambiental, em especial a "Aula das Descobertas". Curitiba, 2011.

FREIRE, P. Pedagogia da autonomia: saberes necessários à prática educativa. ed. 21à. São Paulo. Editora Paz e Terra, 2002.

MELLO, G. N. Formação inicial de professores para a educação básica: uma (re)visão radical. Cadernos de Posgrad, n. 1. Santos: Unisantos: 2000.

MINAYO, M. C. de S. O Desafio do Conhecimento: Pesquisa Qualitativa em Saúde. 7. ed. São Paulo: Hucitec, 2000. 269 p.

MINAYO, M. C. S. Pesquisa social: teoria, método e criatividade. Petrópolis: Vozes, 2001.

MOZZATO, A. R.; GRZYBOVSKI, D. Análise de conteúdo como técnica de análise de dados qualitativos no campo da administração: potencial e desafios. RAC. Revista de Administração Contemporânea (Online), v. 15, p. 731-747, 2011.

REGINALDO, C. C.; SHEID, N. M. J. \& GULLICH, R. I. C. O Ensino de Ciências e a Experimentação. In: IX Seminário de Pesquisa em Educação da Região Sul - ANPED SUL, 2012, Caxias do Sul. Anais do IX Seminário de Pesquisa em Educação da Região Sul - ANPED SUL, 2012.

SANTOS, C. H. dos V., História e filosofia da ciência nos livros didáticos de biologia do ensino médio: análise sobre o conteúdo sobre a origem da vida. Dissertação (mestrado), Universidade Estadual de Londrina, Londrina, 2006.

SCHNEUWLY, B. e DOLZ, J. Os gêneros escolares: Das práticas de linguagem aos objetos de ensino. Revista Brasileira de Educação, no11. 5-17. 1999.

SOUZA, D. C. \& BARROS, M. D. M. Jogos Interativos: Uma Possibilidade no ensino de Ciências para a Educação de Jovens e Adultos. In. III Encontro Nacional de Ensino de Ciências da Saúde e do Ambiente. Niterói, RJ. 2012.

TOMAZETTI, E. Filosofia no ensino médio e seu professor: algumas reflexões. Educação: Revista do Centro de Educação da UFSM, Santa Maria (RS), v. 27, n. 2, jul/dez. 2002. 
VASCONCELOS, F. C. G. C. \& LEÃO, M. B. C. O Vídeo como Recurso Didático para Ensino de Ciências: Uma Categorização Inicial. In: IX Jornada de Ensino, Pesquisa e Extensão-IX JEPEX, Recife-PE. 2009.

VIVEIRO, A. A. Atividades de campo no ensino de ciências: Investigando concepções e práticas de um grupo de professores. 168p. Dissertação (Mestrado em Educação para a Ciência) - Faculdade de Ciência, Universidade Estadual Paulista. Bauru, 2006. 